\title{
Ultrasound Measurements of Anterior Soft Tissue Thickness to Predict Difficult Laryngoscopy in Pregnant Patients
}

\author{
Solak H.E., Yilmaz C., Karasu D., Karaduman I., Korfali G \\ University of Health Sciences Bursa Yuksek Ihtisas Training and Education Hospital, Dept of Anaesthesiology \& Intensive Care, Bursa, \\ Turkey
}

\section{Objective:}

Obstetric patient airway management is becoming important, because of anatomical and physiological changes in the airway related to the pregnancy. The aim of our study was to compare the ultrasound (USG) measurements of 5 different levels of anterior neck soft tissue and other clinical screening tests for determination of difficult laryngoscopy in patients who underwent cesarean section operation with general anesthesia.

\section{Materials and Methods:}

Prospective, observational study included 140 pregnant women (18-45 years old, ASA I-II). Mallampati test, mouth opening, sternomental and thyromental distance, upper lip bite test, and neck circumference were recorded. The distance from the skin to the anterior aspect of the trachea was measured at 5 different levels: hyoid bone (zone 1), tirohyoidmembrane (zone 2), vocal cords (zone 3), thyroid isthmus (zone 4) and suprasternal notch (zone 5) (Fig I-V). An anaesthesiologist who was blind to the clinical screening variables and USG results performed the laryngoscopy. According to Cormack and Lehane's scale, patients were divided into two groups: a grade 1 or 2 was accepted easy laryngoscopy, whereas a grade 3 or 4 was considered difficult laryngoscopy.

Fig I-V:Ultrasound Measurements of 5 Different Levels of Anterior Neck Soft Tissue

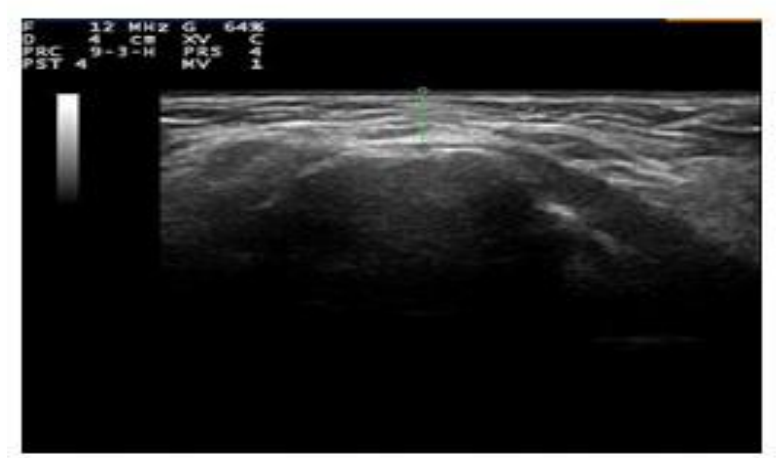

Fig I: Hyoid Bone (Zone I)

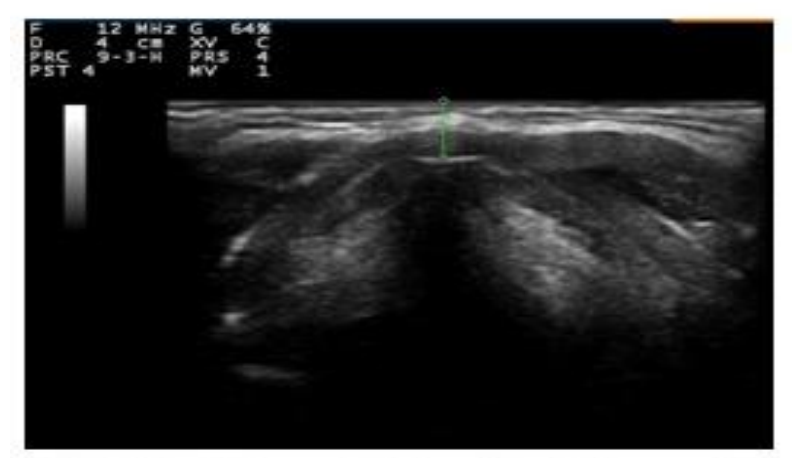

Fig III: Vocal Cords (Zone III)

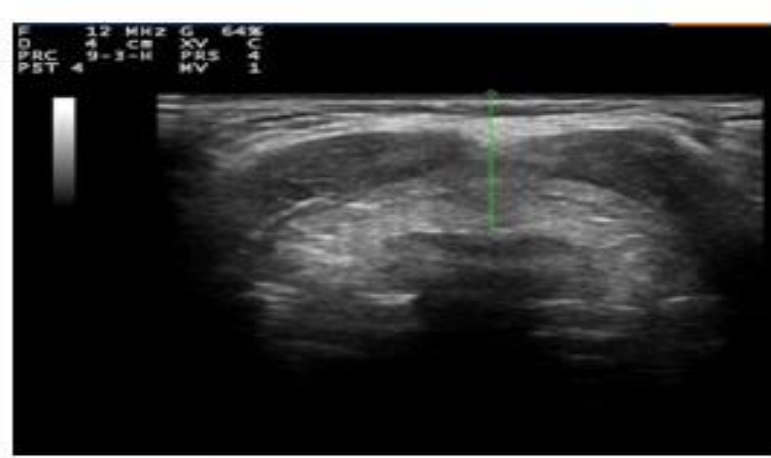

Fig II: Tirohyoidmembrane (Zone II)

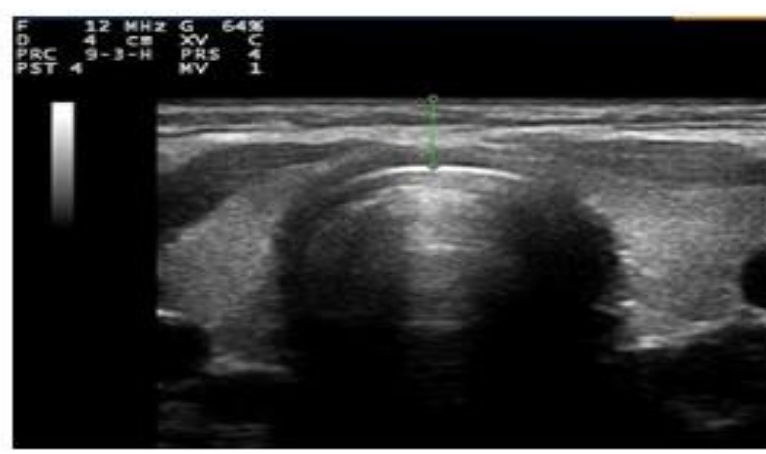

Fig IV: Thyroid Isthmus (Zone IV)

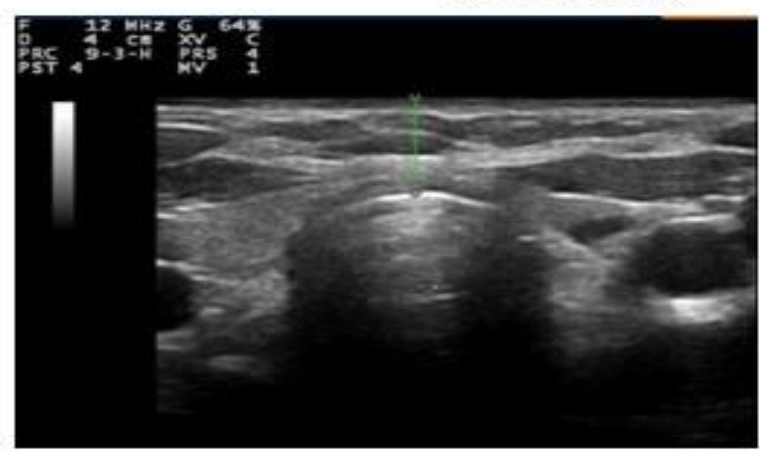

Fig V: Suprasternal Notch (Zone V)
Results:

Twenty of 140 patients were excluded from the study (meeting inclusion criteria $(n=5)$, declined to participate $(n=9)$, other reasons $(n=5)$, and loss of USG recordings $(n=3)) .30$ patients were classified as having difficult laryngoscopy (25\%). All of the patients were entubated succesfully. Amoung the other clinical screening tests for difficult laryngoscopy: limited mouth opening $(<3 \mathrm{~cm})$, high Wilson's Risk Score $(>2)$, large neck circumference ( $>40 \mathrm{~cm}$ ), unable to bite the upper lip, and high mallampati score (III-IV) were found higher in the difficult laryngoscopy group $(\mathrm{p}<0.05)$. Also, BURP maneuver, useage of gum elastic bougie, high intubation difficulty score (IDS $\geq 5$ ), 3 more intubation attempts, airway difficulty rate were significantly higher in the difficult laryngoscopy group $(\mathrm{p}<0.05)$ Uni- and Multivariable Models can be seen on Table I.

Table I: Univariable and Multivariable tests for the ultrasound measurements of 5 different levels of anterior neck soft tissue and other clinical screening tests for determ ination of difficult laryngoscopy

\begin{tabular}{|c|c|c|c|c|c|c|}
\hline & \multicolumn{3}{|c|}{ Univariable Model } & \multicolumn{3}{|c|}{ Multivariable Model } \\
\hline & $\begin{array}{l}\text { Odds } \\
\text { Ratio }\end{array}$ & $\begin{array}{c}95 \% \\
\text { Confidence } \\
\text { Interval }\end{array}$ & $\mathbf{p}$ & $\begin{array}{l}\text { Odds } \\
\text { Ratio }\end{array}$ & $\begin{array}{c}95 \% \\
\text { Confidence } \\
\text { Interval }\end{array}$ & $p$ \\
\hline Age & 1.0 & $0.92-1.09$ & 0.983 & & & \\
\hline Increased Body Mass Index & 1.14 & $0.94-1.39$ & 0.177 & & & \\
\hline Thyromental Distance & 0.86 & $0.58-1.28$ & 0.472 & & & \\
\hline Sternomental Distance & 0.76 & $0.59-0.98$ & 0.034 & & & \\
\hline Ultrasonography Zone I & 37.6 & $0.01->100$ & 0.402 & & & \\
\hline Ultrasonography Zone II & 4.3 & $0.00 \rightarrow 100$ & 0.717 & & & \\
\hline Ultrasonography Zone III & 2.9 & $0.03->100$ & 0.650 & & & \\
\hline Ultrasonography Zone IV & 10.9 & $0.03->100$ & 0.419 & & & \\
\hline Ultrasonography Zone V & 15.7 & $0.04 \rightarrow 100$ & 0.366 & & & \\
\hline Mouth Opening & 0.35 & $0.15-0.86$ & $0.021^{* \star}$ & & & \\
\hline Modified Mallampati Score & 1.70 & $1.00-2.90$ & $0.048^{* \star}$ & & & \\
\hline Wilson Risk Score & 1.79 & $1.18-2.71$ & $0.006^{* *}$ & & & \\
\hline Intubation Difficulty Scale & 0.50 & $0.39-0.64$ & $0.000^{* *}$ & & & \\
\hline Inability to Bite Upper Lip & 2.5 & $1.25-5.0$ & $0.009^{* *}$ & & & \\
\hline Neck Circumference & 1.23 & $1.03-1.48$ & $0.025^{* *}$ & & & \\
\hline Airway Difficulty Rate & 0.03 & $0.01-0.08$ & $0.000^{* *}$ & & & \\
\hline No. of Intubation Atten & 7.06 & $2.71-18.3$ & $0.000^{* *}$ & 7.06 & $2.71-18.3$ & $0.000^{\star \star \star}$ \\
\hline More than Three Attempts & 0.03 & $0.01-0.10$ & $0.000^{* *}$ & & & \\
\hline *BURP Maneuvre & 0.0 & $0.00-0.1$ & $0.000^{* *}$ & & & \\
\hline Gum Elastic Bougie & 0.0 & $0.01-0.1$ & $0.000^{* *}$ & & & \\
\hline
\end{tabular}

*BURP: Backward, Upward, Rightward Pressure **p<0.05

Conclusion(s):

We found that high a mallampati score (III-IV), inability to bite the upper lip, limited mouth opeuseful in preoperative bedside tests to determine difficult laryngoscopyning, large neck circumference and high Wilson's Risk Score were. We believe that the use of BURP maneuver and gum elastic bougie will increase the success rate of endotracheal intubation. In our study, we did not find a statistically significant relationship between difficult laryngoscopy and the distance from the skin to the anterior surface of the trachea when measured with USG. We found that USG measurement of the anterior neck soft tissue has no effective benefit for predicting difficult laryngoscopy in pregnant patients.

Keywords: Airway Management, Laryngoscopy, Ultrasonography, Pregnancy, Neck Circumference.

\section{References:}

1.Ezri T, Gewürtz G, Sessler DI, Medalion B, Szmuk P, Hagberg C, Susmallian S. Prediction of difficult laryngoscopy in obese patients by ultrasound quantification of anterior neck soft tissue. Anaesthesia. 2003;58(11):1111-4.his could be a place for your sources.

2.Pinto J, Cordeiro L, Pereira C, Gama R, Fernandes HL, Assunc J. Predicting difficult laryngoscopy using ultrasound measurement of distance from skin to epiglottis. J Crit Care. 2016;33:26-31.

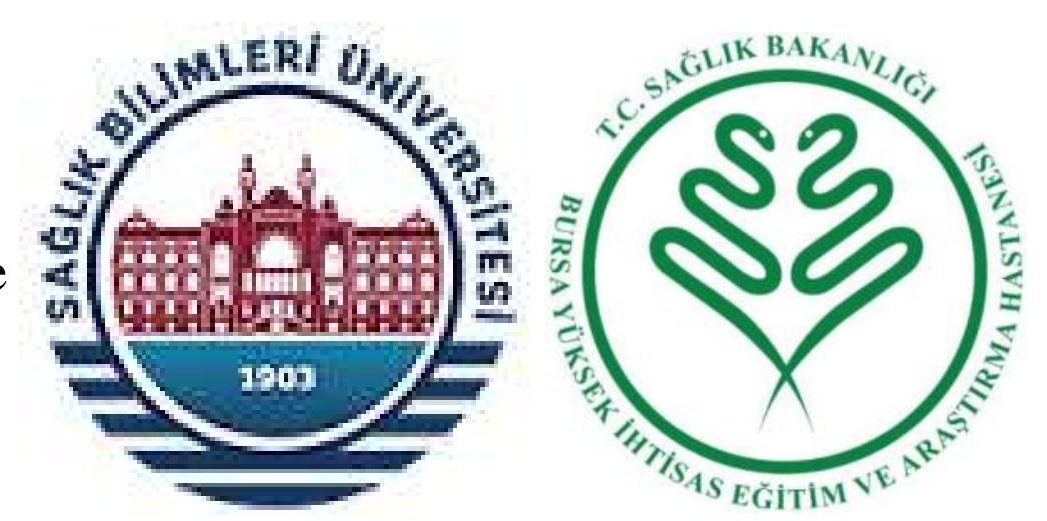

